ISSN 0103-8478

\title{
Qualidade fisiológica de sementes de citros durante o armazenamento em ambiente refrigerado
}

\author{
Physiological quality of seeds of citrus during cooling conditions storage
}

\author{
Tiago Barbosa Struiving ${ }^{I^{*}}$ Daniel Lucas Magalhães Machado ${ }^{\mathrm{I}}$ Dierlei dos Santos ${ }^{\mathrm{I}}$ \\ Dalmo Lopes de Siqueira ${ }^{I}$ Cícero Cartaxo de LucenaI \\ Pedro Henrique Monteiro Matarazzo ${ }^{\mathrm{I}}$
}

RESUMO

Objetivou-se avaliar o efeito do armazenamento sobre a viabilidade das sementes dos porta-enxertos Citradia 1708, Citrandarin 1710, Citrange Carrizo, limoeiro Cravo, Trifoliata Limeira, Rangpur $x$ Swingle 1707 armazenadas em sacolas de polietileno de alta densidade (PEAD) sobre temperatura controlada de $5-7^{\circ} \mathrm{C}$ e umidade relativa do ar de $70 \%$ por 210 dias. Inicialmente e a cada 30 dias foram avaliadas a emergência, índice de velocidade de emergência e o grau de umidade das sementes. $O$ delineamento experimental utilizado foi o inteiramente casualizado, com quatro repetições. Nas condições de armazenamento utilizadas, as sementes do limoeiro Cravo com umidade de $8,03 \%$ ainda conservaram o poder germinativo em $67 \%$, mas, para a manutenção da viabilidade de sementes de Citradia 1708, Citrandarin 1710, Citrange Carrizo, Rangpur $x$ Swingle 1707, o grau de umidade deve estar entre $30-40 \%$. A viabilidade das sementes dos porta-enxertos Rangpur $x$ Swingle 1707, Citradia 1708' e Citrange Carrizo se mantém por até 150 dias.

Palavras-chave: porta-enxerto, germinação, emergência e viabilidade.

\section{ABSTRACT}

Aimed to evaluate the effect of storage on emergence and force of the rootstocks Citradia 1708, Citrandarin 1710, Citrange Carrizo, Rangpur lime, Trifoliata Limeira, Rangpur $x$ Swingle 1707 seeds stored in High density polyethylene (HDPE) at $5-7^{\circ} \mathrm{C}$ and relative humidity of $70 \%$ for 210 days. The emergence, emergence speed index and seed moisture content were performed each 30 days. The experimental design was a completely randomized design with four replications. The storage in that conditions cited showed that the seeds of Rangpur with moisture content inferior to $9 \%$ still showed $66.94 \%$ and 2.03 for germination and IVE, respectively. For the maintenance of the viability of seeds of the rootstocks Citradia 1708, Citrandarin
1710, Citrange Carrizo, Rangpur x Swingle 1707, moisture content could be kept between 35-40\%. Seed viability of the rootstocks Rangpur x Swingle 1707, Citradia 1708 and Citrange Carrizo was maintained for until 150 days.

Key words: rootstock, germination, emergence and viability.

\section{INTRODUÇÃO}

O Brasil lidera o mercado citrícola mundial, com uma produção estimada de 19 milhões de toneladas de laranja na safra 2011/2012 (AGRIANUAL, 2012). As divisas geradas pela exportação de suco de laranja concentrado e a mãode-obra empregada na sua produção fazem das espécies cítricas culturas de grande importância socioeconômica para o país.

A importância do processo de armazenamento, desde o acondicionamento na embalagem até as condições de ambiente em que as sementes são guardadas é de assegurar a sua preservação, garantindo o seu suprimento anual, atuando ainda como instrumento regulador de mercado e na conservação de recursos genéticos em bancos de germoplasma (AGUIAR, 1995; CARVALHO et al., 2002). O fato de as sementes ainda estarem sujeitas ao transporte a longas distâncias, épocas distintas de maturação dos porta-enxertos e semeadura fazem do armazenamento um processo essencial. Assim, o domínio de técnicas de conservação é de grande importância para a citricultura, permitindo aos

IDepartamento de Fitotecnia, Universidade Federal de Viçosa (UFV), Av. PH Rolfs, s/n, 36570-000, Viçosa, MG, Brasil. E-mail: struiving@hotmail.com *Autor para correspondência.

IIEmbrapa Mandioca e Fruticultura Tropical, Cruz das Almas, BA, Brasil. 
viveiristas a produção de mudas em épocas adequadas (SIQUEIRA et al., 2002).

As sementes de citros são comumente acondicionadas em sacos de polietileno e armazenadas em ambientes com refrigeração, por favorecer a sua conservação por períodos maiores sem perdas significativas de viabilidade (HONG \& ELLIS, 1995). Segundo POPINIGIS (1985), geralmente a longevidade é aumentada, conservando-se a semente com baixo grau de umidade e baixa temperatura. No entanto, existem sementes de espécies denominadas recalcitrantes que exigem elevado grau de umidade para sua conservação.

O nível de recalcitrância em sementes varia entre e dentro das espécies e está relacionado ao grau de umidade no momento da dispersão, à tolerância à desidratação, resposta a taxa de secagem, sobrevivência no armazenamento e a resposta às baixas temperaturas de armazenagem (CARVALHO et al., 2002). Assim, as sementes de citros foram classificadas, quanto à tolerância à secagem, como intermediárias, ou seja, entre ortodoxa e recalcitrante, sendo algumas espécies com sementes de caráter mais ortodoxo (KING \& ROBERTS, 1979).

A temperatura ambiental, isoladamente ou em associação com o grau de umidade, tem interferido na conservação das sementes de citros. O armazenamento de sementes de limoeiro 'Cravo' e laranja 'Caipira' com graus de umidade superiores a $30 \%$ em ambiente com temperatura entre 2 e $3^{\circ} \mathrm{C}$ foi possível durante 14 meses; similarmente, MONTENEGRO E SALIBE (1960) observaram vantagens na conservação das sementes de limoeiro 'Cravo' com $25 \%$ de umidade a $8^{\circ} \mathrm{C}$ em relação às armazenadas sob temperaturas mais elevadas. Por outro lado, KING et al. (1981) observaram que sementes com $5 \%$ de umidade e armazenadas a temperaturas abaixo de $5^{\circ} \mathrm{C}$ mantiveram melhor o poder germinativo quando comparadas àquelas armazenadas com grau de umidade mais elevado. Para KOLLER et al. (1993), a conservação de sementes de Poncirus trifoliata foi melhor em geladeira a $5^{\circ} \mathrm{C}$ do que em câmara a $12^{\circ} \mathrm{C}$ e $47 \%$ de umidade relativa.

O objetivo neste trabalho foi avaliar o efeito do armazenamento sobre a viabilidade das sementes de seis diferentes porta-enxertos cítricos.

\section{MATERIAL E MÉTODOS}

O trabalho foi conduzido no Departamento de Fitotecnia da Universidade Federal de Viçosa (UFV), Minas Gerais, em condições de casa de vegetação e laboratório, com sementes dos seguintes porta-enxertos: 'Citradia 1708' (Citrus aurantium x Poncirus trifoliata), 'Citrandarin 1710' (Citrus reticulata - Changsha x English Small - Poncirus trifoliata), 'Citrange Carrizo' (Citrus sinensis (L.) Osb. x Poncirus trifoliata (L.) Raf.), limoeiro 'Cravo' (Citrus limonia Osbeck.), 'Trifoliata Limeira’ (Poncirus trifoliata (L.) Raf.), 'Rangpur x Swingle 1707’ (Citrus paradisi x Poncirus trifoliata - Citrus limonia Osbeck.).

Os frutos maduros foram colhidos no pomar do setor de Fruticultura da UFV em maio de 2007, cortados e as sementes foram retiradas manualmente, removendo-se a mucilagem por meio da lavagem delas com água corrente e cal, sendo a secagem realizada à sombra, sobre papel toalha por 72 horas. As sementes consideradas normais foram contadas e pesadas em balança com precisão de 0,001g, calculando-se o número médio de sementes por quilo e a massa de mil sementes para cada portaenxerto.

Posteriormente, as sementes foram tratadas com o fungicida Captan 500PM (100g i.a. $100 \mathrm{~kg}^{-1} \mathrm{de}$ sementes), colocadas em sacolas de polietileno de alta densidade (PEAD) e armazenadas em câmara fria (temperatura de $5-7^{\circ} \mathrm{C}$ e umidade relativa do ar de $70 \%)$ por 210 dias.

No tempo zero e a cada 30 dias, durante sete meses, foram retiradas amostras para efetuar as seguintes avaliações: determinação do grau de umidade - utilizaram-se duas amostras de cada portaenxerto com 40 sementes através do método da estufa a $105 \pm 3^{\circ} \mathrm{C}$ durante 24 horas, de acordo com BRASIL (1992); emergência - cada semente foi semeada a $1 \mathrm{~cm}$ de profundidade em tubetes cônicos de plástico, com capacidade para $50 \mathrm{~cm}^{3}$ preenchidos com substrato Bioplant $^{\circledR}$ enriquecido com $300 \mathrm{~g} \mathrm{~m}^{-3}$ de Osmocote ${ }^{\circledR}$ na formulação 22-4-8+micronutrientes, totalizando quatro repetições de 24 sementes em delineamento inteiramente casualizado, dispostos em bandejas com capacidade para 96 tubetes. Todas as bandejas permaneceram sob irrigação diária, em função da necessidade hídrica das mudas, e as contagens das plântulas emergidas foram realizadas a partir dos 35 até os 100 dias após a semeadura, com intervalo de cinco dias para cada avaliação, computando-se o número de plântulas normais, expressando o resultado em porcentagem; índice de velocidade de emergência (IVE) - conduzido juntamente com a avaliação de emergência, computando-se o número de plântulas emergidas com um par de folhas (NAKAGAWA, 1999) e, ao final do teste, foi calculado o IVE empregando-se a fórmula proposta por MAGUIRE (1962). 
Os dados climáticos foram coletados a cada hora e as médias diárias de temperatura e umidade relativa do ar foram calculadas segundo metodologia da EMBRAPA (2008).

O delineamento experimental utilizado foi inteiramente ao acaso, cujos dados foram submetidos à análise de variância e de regressão polinomial para o efeito das épocas de armazenamento, sendo as equações selecionadas com base na significância dos seus efeitos.

\section{RESULTADOS E DISCUSSÃO}

O peso de mil sementes é uma informação referente ao tamanho das sementes, assim como do seu estado de maturidade e de sanidade, pois é uma característica varietal influenciada pelo clima, solo, adubação, pragas, patógenos, beneficiamento, grau de umidade e tratamento químico (BRASIL, 2009). O maior peso foi de $244 \mathrm{~g} 1000^{-1}$ sementes do portaenxerto 'Citrange Carrizo', o que representa 4100 sementes $\mathrm{kg}^{-1}$, enquanto o menor valor foi de $77 \mathrm{~g}$ $1000^{-1}$ sementes de limoeiro 'Cravo', representando 13000 sementes $\mathrm{kg}^{-1}$ (Tabela 1).

Pelos dados da figura 1, observa-se que o grau de umidade das sementes dos portaenxertos 'Citradia 1708', 'Citrange Carrizo', 'Rangpur x Swingle 1707’, 'Trifoliata Limeira’ e 'Citrandarin 1710', após a secagem (51, 51, 49, 48 e $41 \%$ respectivamente), foi elevado em relação ao das sementes do porta-enxerto limoeiro 'Cravo' (21\%). No entanto, após 210 dias de armazenagem das sementes, com exceção daquelas do limoeiro 'Cravo' a dos demais porta-enxertos testados, tiveram acentuada redução do grau de umidade, mantendo-se na faixa de 12 a $26 \%$. A maior redução do grau de umidade, aos 210 dias, das sementes do 'Citradia 1708' e 'Citrandarin 1710' (respectivamente, 12 e $13 \%$ ) pode ser atribuída ao menor tamanho delas (Tabela 1), consequentemente, maior superfície específica, permitindo maiores taxas de trocas gasosas com o meio. KING \& ROBERTS (1980) afirmaram que a perda de umidade é mais rápida em sementes de menor tamanho do que em sementes maiores.

Conforme esperado, ao longo do armazenamento, houve perda de viabilidade das sementes, porém foi mais expressiva naquelas dos porta-enxertos recalcitrantes, como no caso do 'Trifoliata', cuja redução no poder germinativo foi rápida, à medida que o grau de umidade foi reduzindo; também a porcentagem de emergência reduziu de $62 \%$ para $8 \%$ nos tempos 0 e 210 dias, respectivamente (Figuras 1 e 2). Resultados semelhantes foram obtidos por OLIVEIRA et al. (2003), quando observaram redução na germinação das sementes de 'Trifoliata' de 96 para 10\% entre os tempos 0 e 210 dias, quando armazenadas em câmara fria.

Na primeira avaliação, após a secagem e sem armazenamento (0 dias), as sementes do porta-enxerto 'Citradia 1708' obtiveram a menor porcentagem de emergência (42\%) com o maior grau de umidade $(51,27 \%)$ em relação à dos demais porta-enxertos. Após 90 dias de armazenamento, a porcentagem de emergência aumentou, atingindo $79 \%$ com 35,5\% de umidade das sementes, mas, a partir do quarto mês, as sementes de 'Citradia 1708' comportaram-se como recalcitrantes, tendo uma rápida queda do poder germinativo com a redução progressiva da umidade, após 210 dias atingiu 12\% de emergência (Figuras 1 e 2).

As sementes dos porta-enxertos 'Citrandarin 1710’, 'Citrange Carrizo’ e 'Rangpur x Swingle 1707' comportaram-se de forma semelhante à das sementes da 'Citradia 1708', tendo um incremento do poder germinativo quando armazenadas por 60 dias em relação às não armazenadas (0 dias) e, posteriormente, acentuada queda da emergência com a redução da umidade das sementes (Figuras 1 e 2). Assim, aos 60 dias, os valores de emergência foram de 75, 92 e 84\% e a umidade de $31 ; 41$ e $40 \%$, respectivamente, para as sementes dos porta-enxertos 'Citrandarin 1710', 'Citrange Carrizo’ e ‘Rangpur x Swingle 1707’.

Em algumas espécies de citros, as sementes são dormentes. Assim, o fato de alguns porta-enxertos

Tabela 1 - Massa de 1000 sementes e número de sementes por quilograma de seis porta-enxertos de citros.

\begin{tabular}{lcc}
\hline Porta-enxertos & Peso de 1000 sementes (g) & No de sementes kg $^{-1}$ \\
\hline Citradia 1708 & 125,00 & 8.000 \\
Citrandarin 1710 & 125,00 & 8.000 \\
Citrange Carrizo & 243,90 & 4.100 \\
Limoeiro ‘Cravo' & 76,90 & 13.000 \\
Trifoliata Limeira & 198,00 & 5.050 \\
Rangpur x Swingle 1707 & 177,00 & 5.650 \\
\hline
\end{tabular}




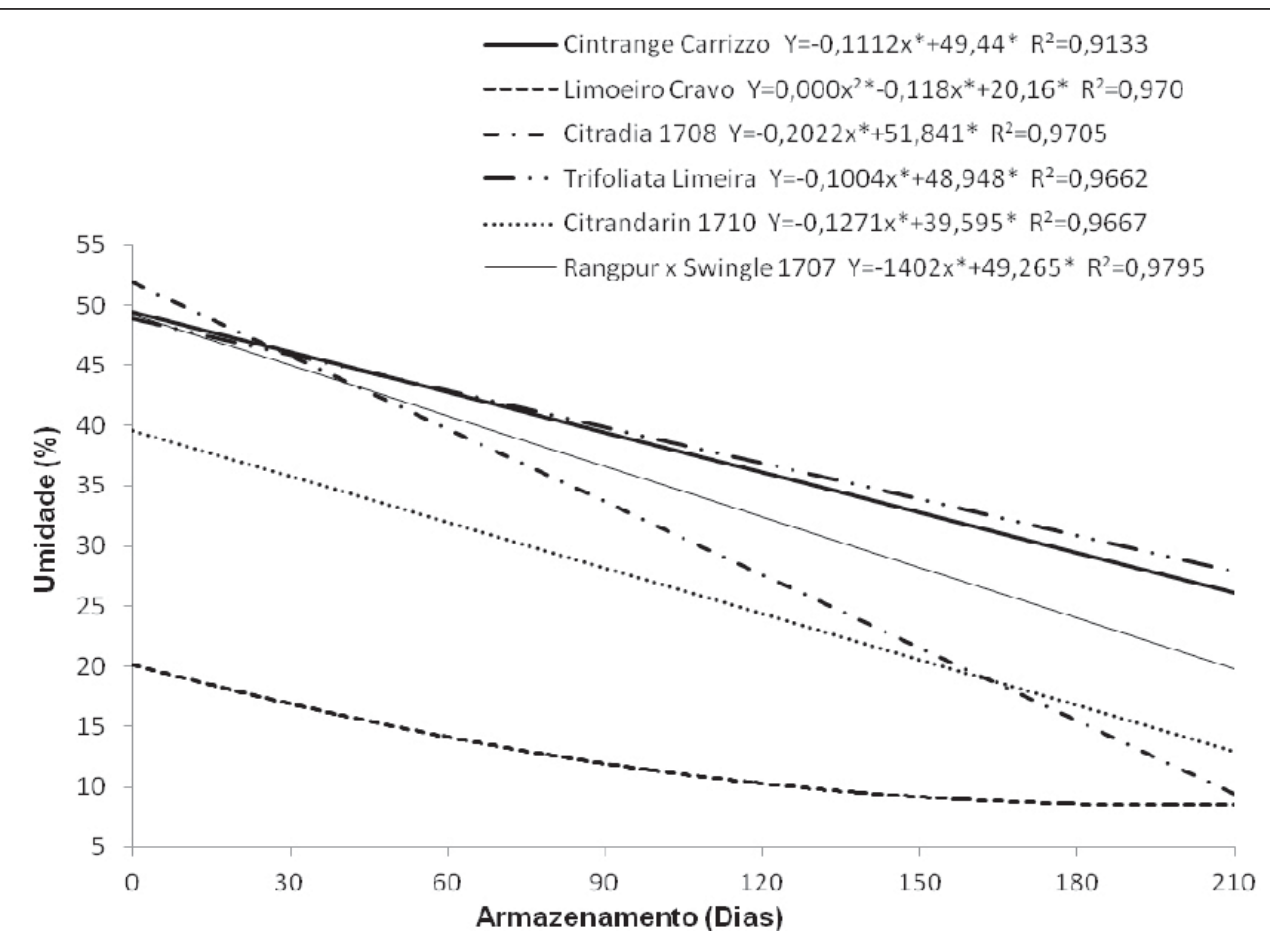

Figura 1 - Grau de umidade (\%) de sementes de seis porta-enxertos de citros em função do armazenamento (Dias).

**, *; Significativo a 5\% e 1\% de probabilidade, respectivamente, pelo teste F.

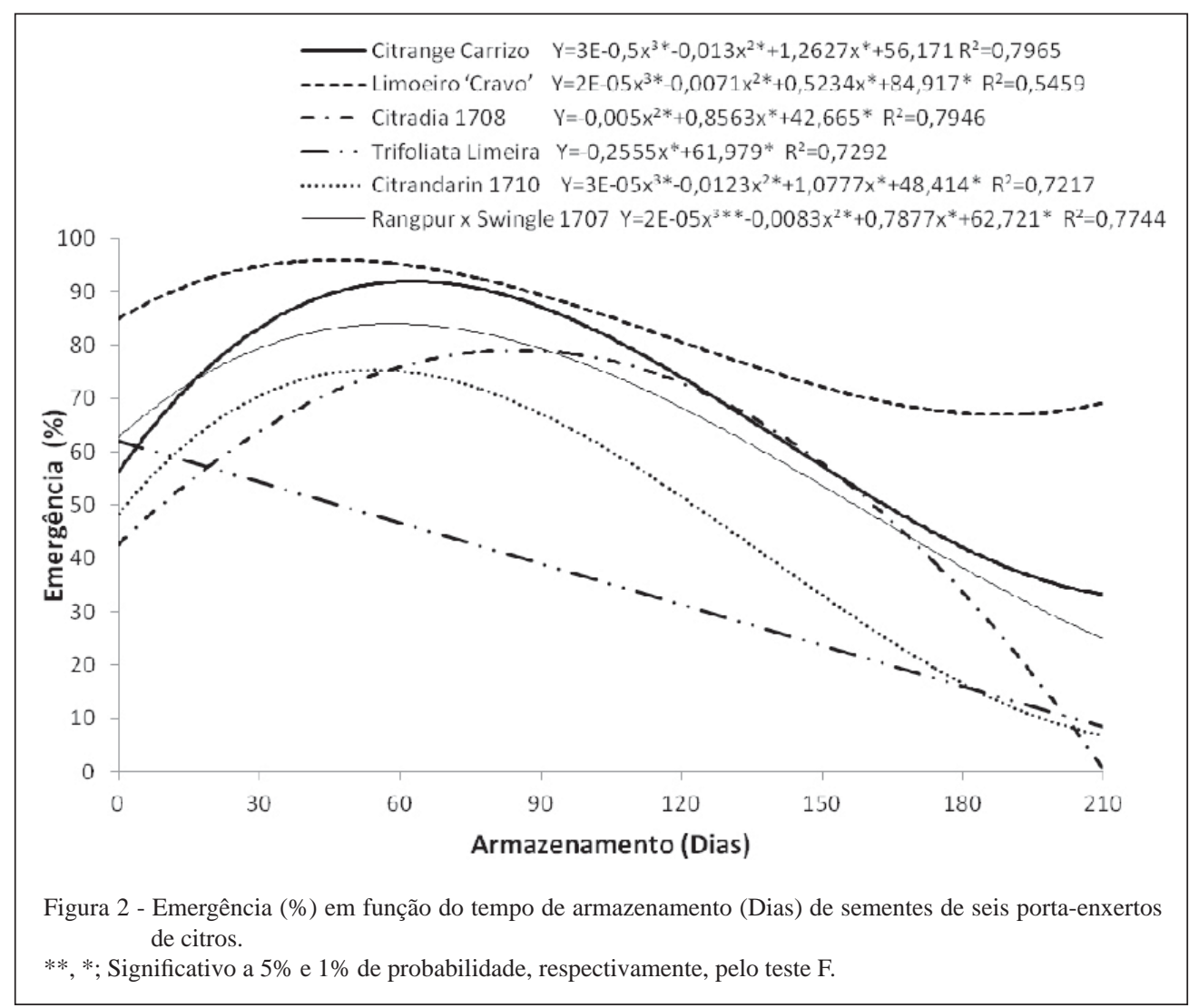

Ciência Rural, v.43, n.10, out, 2013. 
obterem aumento do poder germinativo nas sementes avaliadas após 60 e 90 dias de armazenamento em relação àquelas semeadas imediatamente após a secagem (0 dias) pode ser devido à quebra dessa dormência pelo incremento da temperatura ambiente durante a condução dos testes (Figura 3), visto que a casa de vegetação não possuía controle de condições ambientais. Outra razão para o aumento do poder germinativo está relacionada ao fato de as sementes atingirem um grau de umidade ideal depois de armazenadas, pois existe um nível crítico de umidade, no qual o grau de umidade na semente deve ser suficiente para evitar o desenvolvimento de microorganismos e proporcionar as reações metabólicas essenciais à manutenção da viabilidade (OLIVEIRA et al., 2003).

Apesar de a redução da umidade parecer responsável pela ausência de germinação das sementes em algumas espécies de citros, as sementes do limoeiro ‘Cravo' mantiveram o poder germinativo na faixa de 85 a 69\%, mesmo com menor grau de umidade, variando de 20,6 a 7,9\%, portanto, não demonstrando em nenhum momento caráter recalcitrante. Esse resultado foi diferente do obtido por CARVALHO et al. (2002) quando observaram que as sementes de limoeiro 'Cravo' comportam-se como recalcitrantes a partir do sexto mês de armazenamento, principalmente, para as amostras acondicionadas em embalagens semipermeável e permeável, resposta possivelmente devido à perda excessiva de umidade permitida pelas embalagens utilizadas. No entanto, MUMFORD \& PANGGABEAN (1982) constataram que as sementes do porta-enxerto limoeiro 'Cravo' tiveram boa tolerância à menor umidade para o armazenamento (6 a 8\%), resultados semelhantes aos obtidos por SIQUEIRA et al. (2002), ao observarem que graus de umidade ligeiramente inferiores a 5\% não limitaram a germinação das sementes desse porta-enxerto, armazenadas por 150 dias.

Após 150 dias de armazenamento, as sementes dos porta-enxertos limoeiro 'Cravo', 'Rangpur x Swingle 1707', 'Citradia 1708' e 'Citrange Carrizo' estavam com boa viabilidade, com cerca de 71, 62, 59 e 54\% de emergência e IVE de 2,36; 1,33; 1,74 e 1,84, respectivamente, (Tabela 2), enquanto a viabilidade das sementes dos portaenxertos 'Trifoliata' e 'Citrandarin 1710' era baixa, com 23,7 e 34,6\% de emergência e IVE de 0,41 e 1,03 , respectivamente.

Os índices de velocidade de emergência (IVE) comprovam que as sementes do limoeiro 'Cravo', apesar do menor grau de umidade em relação a dos demais, obteve, em todas as avaliações, altos valores de IVE, sendo o único porta-enxerto a ter sementes viáveis aos 210 dias de armazenamento, com IVE de 2,03 e 69\% de emergência.

\section{CONCLUSÃO}

Nas condições de armazenamento utilizadas, as sementes do limoeiro 'Cravo' com percentual de umidade de $8,03 \%$ são conservadas com poder germinativo de $69 \%$ por 210 dias. Nas mesmas condições de armazenamento adotadas, as sementes dos porta-enxertos 'Rangpur x Swingle 1707’, ‘Citradia 1708' e 'Citrange Carrizo’ são

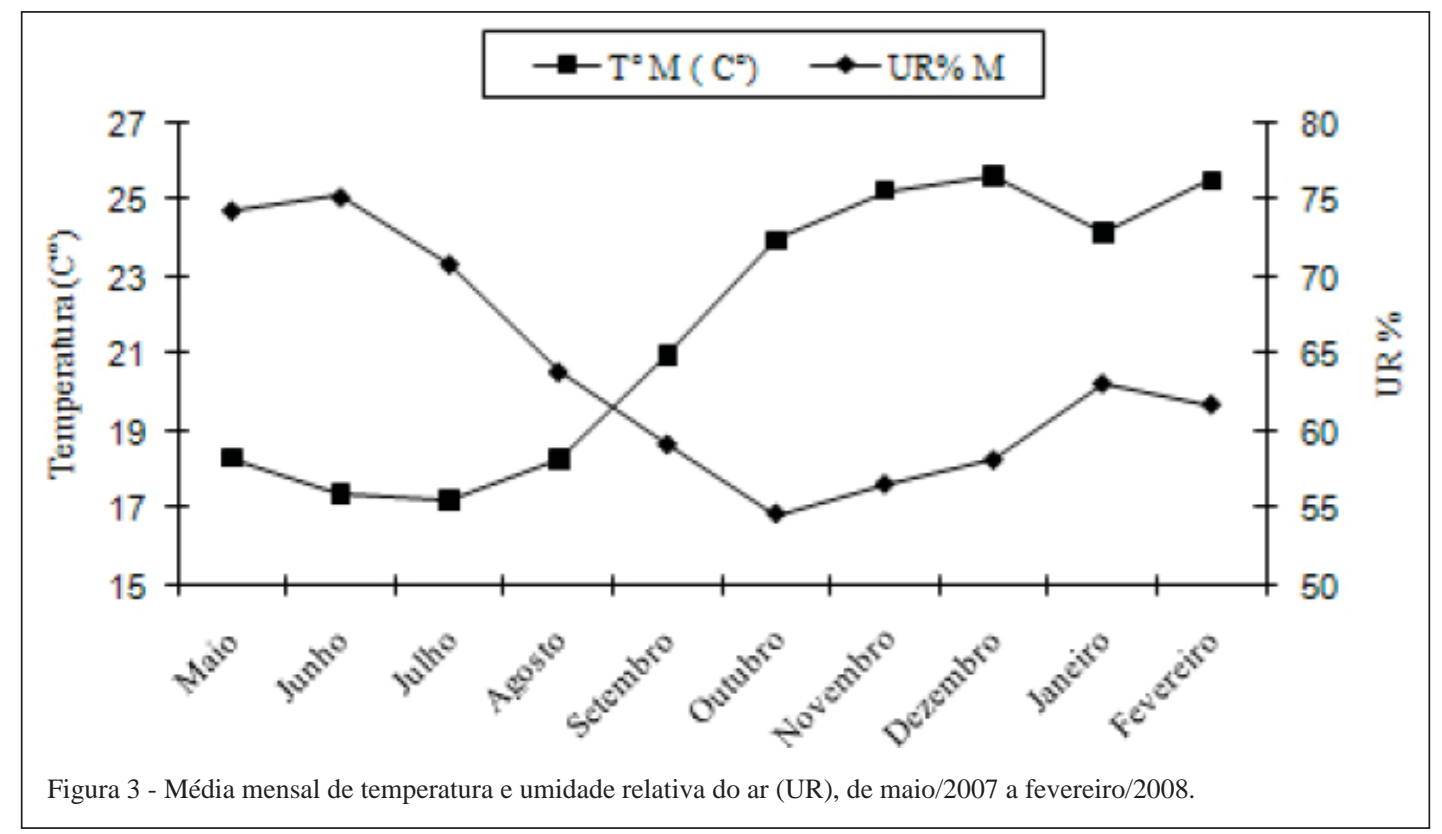

Ciência Rural, v.43, n.10, out, 2013. 
Tabela 2 - Índice de velocidade de emergência (IVE) de plântulas oriundas de sementes de porta-enxertos de citros em função do tempo de armazenamento (dias).

\begin{tabular}{|c|c|c|c|c|c|c|c|c|}
\hline \multirow{2}{*}{ Porta-enxertos } & \multicolumn{8}{|c|}{----------------------------------------------'Armazenamento (dias) -------------------------------------------- } \\
\hline & 0 & 30 & 60 & 90 & 120 & 150 & 180 & 210 \\
\hline Citrange Carrizo & 1,17 & 2,16 & 2,07 & 2,27 & 2,21 & 1,84 & 1,04 & 0,72 \\
\hline Limoeiro ‘Cravo’ & 2,52 & 1,61 & 2,37 & 2,00 & 1,78 & 2,36 & 1,99 & 2,04 \\
\hline Citradia 1708 & 1,11 & 1,46 & 1,11 & 1,03 & 113 & 1,74 & 0,29 & 0,05 \\
\hline Trifoliata Limeira & 1,52 & 1,15 & 0,80 & 0,82 & 0,63 & 0,41 & 0,30 & 0,01 \\
\hline Citrandarin 1710 & 0,92 & 1,02 & 1,37 & 0,89 & 0,84 & 1,03 & 0,20 & 0,02 \\
\hline Rangpur x Swingle 1707 & 1,67 & 1,60 & 1,50 & 1,69 & 1,43 & 1,33 & 0,90 & 0,39 \\
\hline
\end{tabular}

conservadas por até 150 dias, sendo o percentual de umidade ideal entre $30-40 \%$ para a manutenção da viabilidade das sementes.

\section{REFERÊNCIAS}

AGRIANUAL. Anuário da Agricultura Brasileira. São Paulo: FNP Consultoria e AgroInformativos, 2012. 512p.

AGUIAR, I.B. Conservação de sementes. In: SILVA, A. et al. (Coord.). Manual técnico de sementes florestais. São Paulo: Instituto Florestal, 1995. p.33-44. (Série Registros, 14).

BRASIL. Ministério da Agricultura e Reforma Agrária. Regras para análise de sementes. Brasília: SNAD/DNDV/CLAV, 1992. 365p.

BRASIL. Ministério da Agricultura, Pecuária e Abastecimento. Regras para análise de sementes. Secretaria de Defesa Agropecuária. Brasília: MAPA/ACS, 2009. 395p.

CARVALHO, J.A. et al. Qualidade de sementes de limãocravo (Citrus limonia Osbeck) durante o armazenamento. Revista Brasileira de Sementes, Londrina, v.24, n.1, p.286298, 2002. Disponível em: <http://dx.doi.org/10.1590/S010131222002000100040>. Acesso em: 20 jul. 2010.

EMBRAPA UVA E VINHO. Dados meteorológicos. 2008. Disponível em: <http://www.cnpuv.embrapa.br/produtos/meteorologia/ jales-coordenadas.html>. Acesso em: 28 maio, 2009.

HONG, T.D.; ELLIS, R.H. Interspecific variation in seed storage behavior within two genera - Coffea and Citrus. Seed Science and Technology, Zürich, v.23, n.1, p.165-181, 1995.

KING, M.W.; ROBERTS, E.H. The storage of recalcitrant seeds: achievements and possible aproaches. Rome: IBPGR, 1979. 22p.

KING, M.W.; ROBERTS, E.H. Maintenance of recalcitrant seeds in storage. In: CHIN, H.F.; ROBERTS, E.H. (Ed.). Recalcitrant crop seeds. Kuala Lumpur: Tropical, 1980. p.53-89.
KING, M.W. et al. The dry storage of Citrus seeds. Annals of Botany, London, v.48, n.6, p.865-872, 1981.

KOLLER, O.L. et al. Efeito da umidade, temperatura de estocagem e duração da estocagem sobre a germinação de Poncirus trifoliata e de outros porta-enxertos de cítrus. Revista Brasileira de Fruticultura, Cruz das Almas, v.15, n.1, p.27-33, 1993.

MAGUIRE, J.D. Speed of germination - aid in selection and evaluation for seedling emergence and vigor. Crop Science, Madison, v.2, n.2, p.176-177, 1962.

MONTENEGRO, H.W.S.; SALIBE, A.A. Conservação de sementes de porta enxertos para Citrus. Revista de Agricultura, Piracicaba, v.35, n.2, p.109-135, 1960.

MUMFORD, P.M.; PANGGABEAN, G. A comparison of the effects of dry storage on seeds of citrus species. Seed Science and Technology, Zurich, v.10, n.2, p.257-266, 1982.

NAKAGAWA, J. Testes de vigor baseados no desempenho das plântulas. In: KRZYZANOWSKI, F.C. et al. Vigor de sementes: conceitos e testes. Londrina: ABRATES, 1999. p.2.1-2.24.

OLIVEIRA, R.P. et al. Procedimentos para o armazenamento de sementes de Poncirus trifoliata (L.) Raf. Revista Brasileira de Fruticultura, Jaboticabal, v.25, n.3, p.461-463, 2003. Disponível em: <http://dx.doi.org/10.1590/S0100-29452003000300025>. Acesso em: 22 jul. 2010.

POPINIGIS, F. Fisiologia de sementes. Brasília: AGIPLAN, 1985. 289p.

SIQUEIRA, D.L. et al. Germinação de sementes de portaenxertos de Citros após o armazenamento em ambiente refrigerado. Revista Brasileira de Fruticultura, Jaboticabal, v.24, n.2, p.317-322, 2002. Disponível em: <http://dx.doi. org/10.1590/S0100-29452002000200009>. Acesso em: 22 jul. 2010. 